\title{
Vessel Lesion Identification
}

National Cancer Institute

\section{Source}

National Cancer Institute. Vessel Lesion Identification. NCI Thesaurus. Code C119569.

The identification of a non-neoplastic or neoplastic pathologic process taking place within a vessel. 